\title{
Manufacturing of Tattoo Ink Products Today and in Future: Europe
}

\section{Ralf Michel}

TIME - Tattoo Ink Manufacturer Europe, Neuburg am Rhein, Germany

\begin{abstract}
The article describes the European market situation and the legal framework in Europe. It shows the state-of-theart production under ISO 9001:2008 quality management and describes the future of tattoo ink production based on good manufacturing practice guidelines for tattoo inks.

(c) 2015 S. Karger AG, Base
\end{abstract}

\section{Definition of Tattooing and Permanent Make-Up}

'Tattooing is a practice whereby a permanent skin marking or design (a 'tattoo') is administered by intradermal injection of products consisting of colorants and auxiliary ingredients' [1].

'A permanent make-up (PMU) consists of colorants and auxiliary ingredients which are injected intradermally for the purposes of enhancing the contours of the face' [1].
The following text addresses the use of tattoo ink for both purposes because both products are regulated in the same way.

\section{European Market Situation}

Most inks being used for tattoos are manufactured outside of Europe (estimated at 70$80 \%)$. American products used by professional artists are dominating the market, and inks from Asia are mainly distributed to nonprofessionals.

Permanent make-up inks are mainly manufactured in Europe (estimated at 70-80\%), and only a few products are imported from America and Asia [2].

European manufacturers of inks are mainly located in England, Germany, France, Italy and Spain. There are approximately 30 companies 
that produce tattoo inks in Europe. Many permanent make-up inks are private-label products manufactured in Germany or Italy.

\section{Legal Situation and Market Control}

The resolution ResAP(2008)1 on the requirements and criteria for the safety of tattoos and permanent make-up (superseding resolution ResAP(2003) 2 on tattoos and permanent makeup) can be considered as state-of-the-art for the manufacturing of tattoo inks.

Only a few European countries have adopted national regulations on tattoo inks (Netherlands, Germany, France, Spain, Sweden, Switzerland, and Norway), and some are using the resolution to control tattoo inks (Italy, Slovenia, Denmark and Austria). Denmark and Austria have wellprepared national regulations based on ResAP(2008)1 but are awaiting further steps of the European Commission.

Currently, manufacturers of tattoo inks have to follow many national regulations. In countries with national regulations, ink manufacturers are controlled by the authorities, and in other countries, such as the United Kingdom, there is no control at all.

In Spain, the agency controlling medical products (Agencia Española de Medicamentos y Productos Sanitarios) is responsible for tattoo inks, and these products need to be homologated. The rules of this homologation are not clear, and there are only a few homologated products. Most artists in the tattoo industry use non-homologated products. This information shows that over-regulation cannot create a safer market for consumers.

ResAP(2008) 1 could only be a first step towards the regulation of tattoo inks. There is a scientific knowledge gap with regard to the process of tattooing and what happens when inks enter the body. For this reason, cosmetic regulations are used to create prohibited ingredient lists. In gen- eral, no ingredients that are forbidden for use in cosmetic products can be used in tattoo inks. All other ingredients that are not regulated in cosmetics can be used. Some colourants that are allowed in cosmetics but have been identified as dangerous for tattoos have been added to the prohibited list.

\section{Current Situation in Europe}

Manufacturers in continental Europe have reformulated their inks and avoid ingredients that are banned for use in tattooing according to ResAP(2008)1. Some companies have established a system of raw material management, defining and controlling the quality of raw materials used in their products.

A risk assessment should be performed according to ResAP(2008)1, but in fact, there is currently no guideline for the risk assessment of tattoo inks, and there is still a scientific gap.

An ad hoc group on the safety of tattoos and permanent make-up of P-SC-COS of the Council of Europe presented a draft version, entitled 'Towards a Toxicological Risk Assessment of Tattoo Chemicals and Inks' [3], which can be used as a guideline for the risk assessment of tattoo inks in the near future and also describes the existing scientific gap.

The biggest problems in the past were the microbiological contamination of inks and the presence of carcinogenic aromatic amines and carcinogenic polycyclic aromatic hydrocarbons (PAHs).

Inks manufactured today in countries with national regulations are much safer than they were 10 years ago. The microbiological quality of today's products is good, and the contamination of inks is a minor problem now compared with the beginning of this century. Inks are delivered sterile and are formulated to remain in microbiologically stable conditions after opening.

Pigment Yellow 74 has been associated with many reports of o-anisidine, which is a carcinogenic aromatic amine in tattoo inks. Most 
European manufacturers have now replaced this pigment. Both resolutions, ResAP(2003)2 and ResAP(2008)1, have significantly improved ink quality with regard to carcinogenic aromatic amines, and they are currently found in very few inks manufactured in Europe.

PAHs are present in most carbon black pigments on the market. There are very few pigments available that fulfil the requirements for tattoo inks, and it is difficult for manufacturers to find them and choose the best one for their inks. Many European producers of tattoo inks have solved this problem within the last years, but there are still products on the market that do not comply with the recommendations of $\operatorname{ResAP}(2008) 1$.

\section{Problems for Ink Manufacturers Today}

Trying to follow the resolutions and national regulations in Europe is associated with the following problems for manufacturers:

\section{Lack of Harmonised Analytical Methods}

National laboratories and most ink manufacturers use a microwave digestion method, and most manufacturers of permanent make-up inks use a cosmetic method for analysing nickel in aqueous solutions. The results obtained with these two methods have been surprisingly different. Using the cosmetic method, ink has been found to be 'nickel free', but with the microwave digestion method, $60 \mathrm{ppm}$ or more of nickel have been detected. There is an easy explanation for this discrepancy, which is that the 'products containing nickel around $60 \mathrm{mg} / \mathrm{kg}$ are based on iron oxides' [4].

The same problem occurs with PAH analyses, which depend on the solvent, temperature and time. Using the method of the US Food and Drug Administration according to requirement 21 CFR Section 178.3297, it is possible to manufacture black carbon-based inks (which comprise more than $98 \%$ of all black inks on the market) according to the demands of the resolution. Us- ing another method might result in the detection of higher pigment levels.

The same problems occur with analyses of carcinogenic aromatic amines. Using the wrong method will result in negative findings when in fact pigments are able to separate into forbidden compounds.

\section{Lack of Guidelines for Risk Assessment}

There is currently no clear way to make a risk assessment, and manufacturers only collect available data for raw materials.

\section{Lack of Guidelines for Good Manufacturing Practice (GMP)}

Is the cosmetic GMP the correct guideline, or should the GMP for the manufacturing of sterile pharmaceuticals be followed? In 2005, TIME published a draft GMP guideline stating that tattoo inks should be treated comparable to class $2 \mathrm{~b}$ medical device products (implantable devices and long-term surgically invasive devices) [5].

Finally, the market situation itself makes it difficult to apply changes to manufacturing processes. Without common regulations throughout Europe and for imported products, competitors have very low costs compared to European manufacturers in regulated countries. The pigments that are currently used to create inks are much more expensive, and the quality management system required to manufacture a safe product is costly and includes the management of raw materials and additional analyses. The current market prices of tattoo inks do not allow for full compliance with GMP production guidelines.

\section{Ink Production Today and Quality Management}

Figure 1 shows a simplified flow chart depicting how to manage ink production under ISO 9001: 2008, starting with the delivery of raw materials. Not shown in the figure is the purchasing process, 


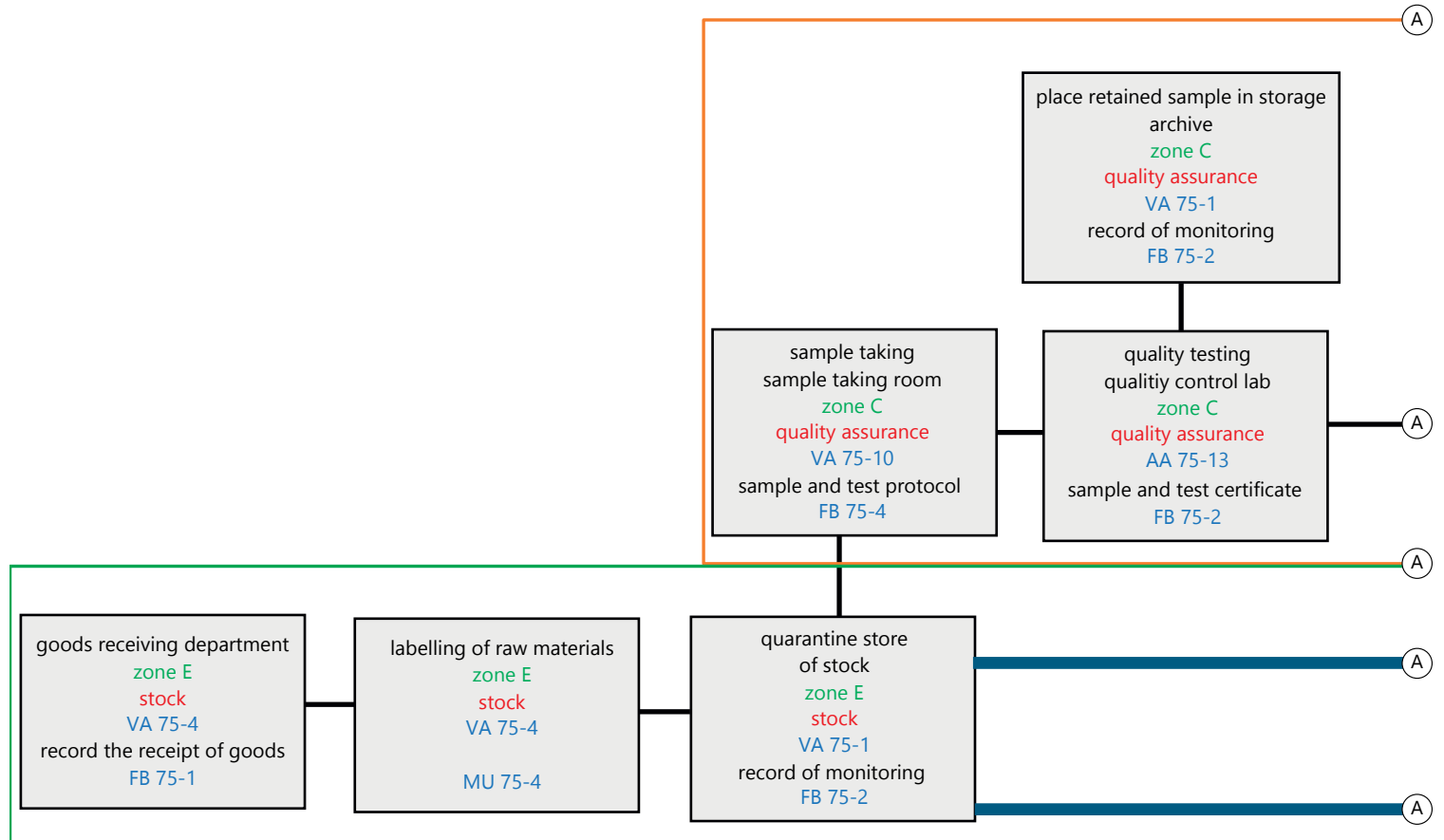

Fig. 1. Flow process chart - good manufacturing practice of tattoo inks.

including the definition of quality parameters for the raw materials.

The process must be described in process instructions (marked VA) and work instructions (marked AA). Forms are defined (marked FB) and used for documentation.

It is necessary to designate one person to be responsible for each step, and the same person must not carry out production and quality management.

For production in a cleanroom, a zone is used to indicate the conditions. This manner of pro- duction is for non-sterile inks. The sterilisation of inks occurs after the filling and sealing of the final container. The zones are defined according to the GMP of sterile medicinal products. Zone E is located outside of the cleanroom.

The first step is the receipt and labelling of the raw material and the first check of documents. The material is stocked in a quarantine store. From the quarantine store, it is transferred to a sampling room, where samples are taken for analysis and testing and retained for documentation. 


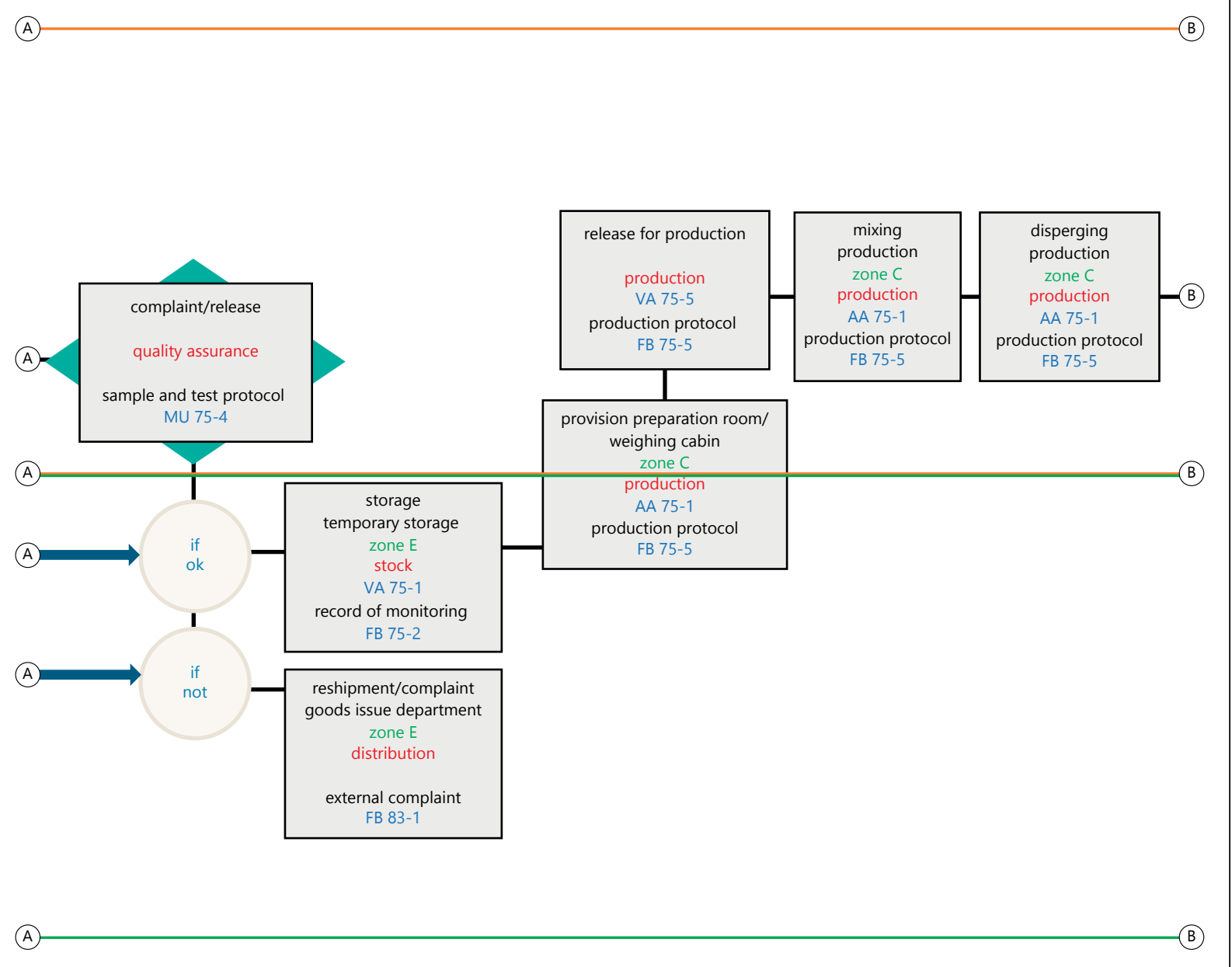

Fig. 1. Continued.

After quality control, the raw material is stocked in a raw material store if all tests have been passed. If the raw material does not pass the tests, it is returned to the supplier or discarded.

In the preparation room (weight cabin), all ingredients are checked again and weighed according to the manufacturing protocol. Then, the ink is mixed and dispersed, following the work instructions. In-process controls guarantee a constant quality of the manufactured product. The ink is than checked again, and if it complies with the standards and reference samples, it is sent to the filling department. If the ink does not comply with the internal standard, it is quarantined.

The next step is the filling and sealing of the product. Sterilisation is carried out during this step, after which the product is again quarantined unless it is released by the quality safety department with proof of sterility.

The inks are than labelled and packaged with all necessary information, including sterilisation batch data. After a final inspection of quality, including packaging and labelling, the inks are released for sale. 


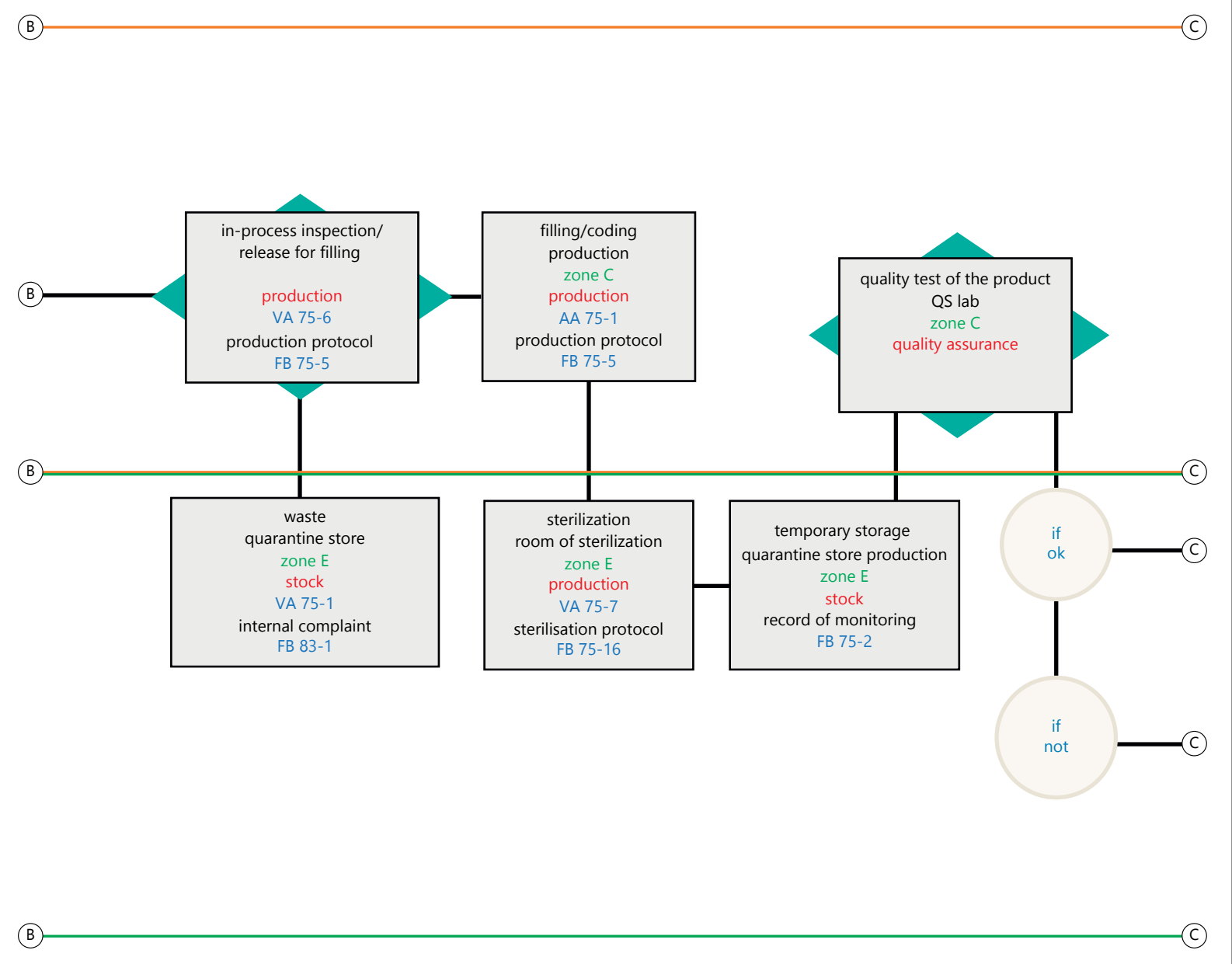

Fig. 1. Continued.

Guidelines for the GMP of tattoo inks are shown in figure 2, which depicts aspects of GMP production.

An effective quality assurance (QA) system involving management and personnel of various departments needs to be established. It is necessary to have personnel with the skills necessary to achieve QA objectives, and these individuals need regular training in the theory and application of QA and GMP.

For the personnel and premises, hygiene programmes are obligatory. Premises and manufac- turing equipment need strict hygiene standards to avoid contamination and any adverse effects. Premises and equipment critical for maintaining the quality of products need appropriate validation.

Production must be organised according to GMP with pre-established instructions and procedures. Documentation and the investigation of process deviations and product defects are necessary. It is also important to have technical and/or organisational measures in place to avoid cross-contamination. The validation of new manufacturing processes and those that have 

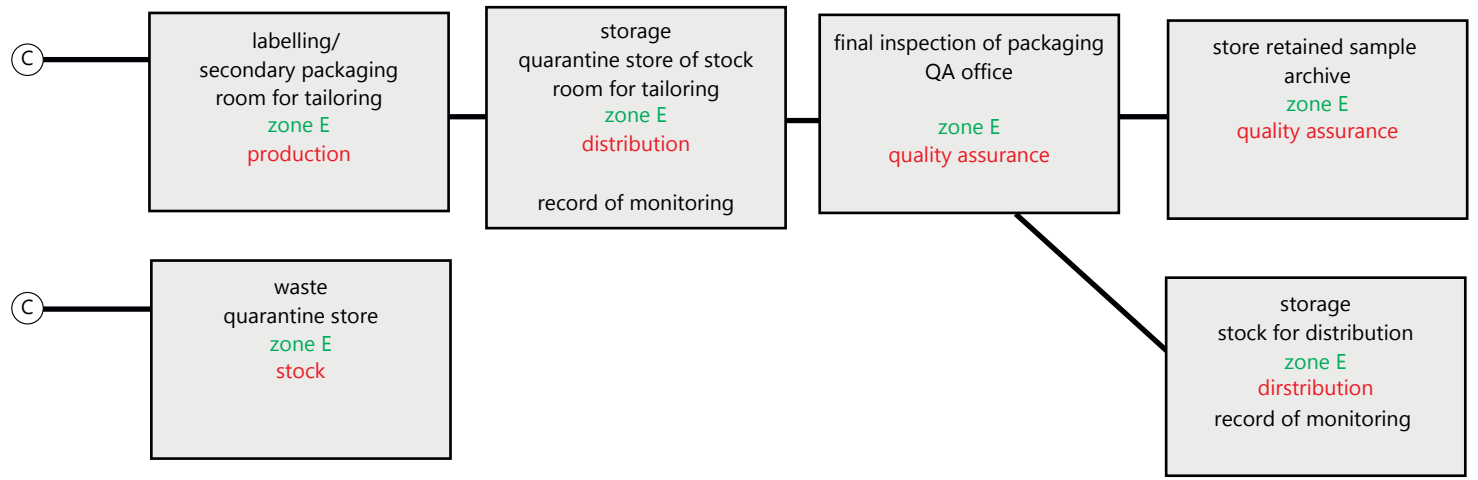

(C)

Fig. 1. Continued.

substantially changed is essential for production. Critical phases of the manufacturing process need revalidation.

The company should establish a system of documentation covering manufacturing operations and the trace history of the manufacture of each batch. For electronic or other data processing systems, it is necessary to prove that data are appropriately stored during the period of question.

For quality control and labelling, it is necessary to have a person who is qualified and independent of production. The quality control laboratory is responsible for the starting materials, packaging materials, and intermediate and finished products. Contract laboratories may be used.

The final control of the finished product before its release on the market includes the assessment of production conditions, in-process controls, manufacturing documents and conformity of specifications. Samples of the finished product for each batch retained must be stored for a minimum of 1 year after the expiration date, and samples of certain raw materials must be stored for 2 years after the release of the product. 
Fig. 2. Aspects of GMP production.

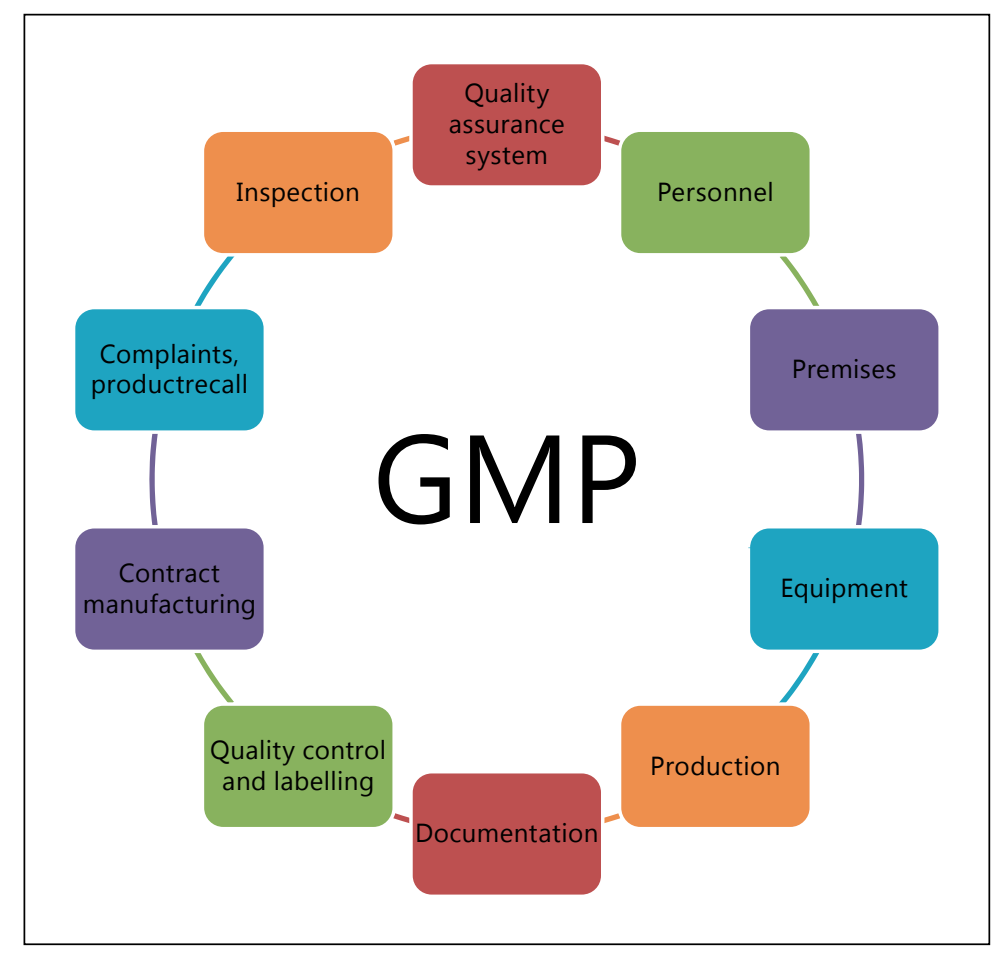

It is possible to use a contract manufacturer. A written contract documents the responsibility of each party, and the contract acceptor has to respect the principles and guidelines of GMP and to submit to inspections carried out by competent authorities.

After the release of the product on the market, it is necessary to examine and record complaints regarding defects in the product and to inform the competent authorities of any defect that could result in a recall or restriction on supply. A recall must be prepared for urgent actions.

Finally, states have to inspect production to ensure adherence to the principles and guidelines of GMP and to exchange information with other competent authorities. The manufacturer has to ensure that manufacturing operations are being carried out according to GMP and provide authorisation. The manufacturer also must perform regular self-inspections.

\section{Summary}

There are still many steps necessary to achieve the common regulation of tattoo inks in Europe and many questions to be answered. It must be accepted that there are still scientific gaps with regard to tattooing that need to be researched in the future. There is a lack of sufficient testing methods to get all data for a full risk assessment.

Despite these problems, it is still possible to start regulating tattoo inks. As a first step, it will be necessary to set up harmonised analytical methods. Based on these methods, the limits set in ResAP(2008)1 have to be reviewed.

With guidelines available for the safety assessment of tattoo inks by the Council of Europe, it is possible to create a first common regulation based on the Council of Europe resolution ResAP(2008) 1 for all European countries and for importers. 


\section{References}

1 Council of Europe: 2. Definitions; in: Resolution ResAP(2008)1 on requirements and criteria for the safety of tattoos and permanent make-up (superseding Resolution ResAP(2003)2 on tattoos and permanent make-up). Council of Europe, 2008.

2 Internal marked review by TIME - Tattoo Ink Manufacturers of Europe.
3 Council of Europe, Final draft 18-092014 PA/PH/COS (10) 27 2R.

4 Prior G: Tattoo Inks: Analysis, Pigments, Legislation: An Introduction to Tattoo Inks, Their Analysis, Pigments in Use, Their Chemical Classes, Present Legislation in Europe, Problems Arising from Incomplete Laws, Quantification of Pigments and Metals in the Skin. epubli GmbH, 2014, p 62.
5 TIME - Tattoo Ink Manufacturer of Europe: Good Manufacturing Practice of Tattoo Inks, 2005.

Ralf Michel

DC-TP Europe $\mathrm{GmbH}$

Lotsenstrasse 10

DE-76776 Neuburg am Rhein (Germany)

E-Mail contact@time-online.eu 